Section of Detention under the Mental Health Act 1983: 26 (14 men, 12 women) were detained under Section 2, 16 (five men, 11 women) under Section 3, and eight (seven men, one woman) under Sections $37 / 41$ (restricted patients).

Diagnoses: Twelve (four men, eight women) were suffering from schizophrenia; 17 (ten men, seven women) paranoid schizophrenia; 16 (seven men, nine women) manic depressive psychosis; two men psychopathic disorder and three men mental impairment.

Outcome: In 40 cases ( 20 men, 20 women) the patients were not discharged. In two (one man, one woman) a decision was deferred. One man was granted trial leave. Five (two men, three women) were absolutely discharged and two men were conditionally discharged.

Observations: There was a preponderance of patients $(14 / 50)$ in the 26 to 30 age group. Section 2 cases accounted for about half $(26 / 50)$ of the total. No restricted patients were aged over 45 . Far more restricted patients were male than female (ratio 7:1). Schizophrenia and paranoid schizophrenia together were nearly twice as frequent as manic depressive psychosis. Cases of manic depressive psychosis were more frequently discharged than patients with other diagnoses.

Some of the results were predictable, others less so. Compared with the schizophrenias, manic depressive illness can run a cyclical course with acute exacerbations and rapid improvements. This would account for more manic depressive patients being under the short term order, Section 2, and being more likely to gain discharge. On the other hand, the schizophrenias, running a longer and less rapidly fluctuating course, were more frequently detained under Section 3. Paranoid patients might be more likely to seek redress of their status through the Tribunal. One in seven cases was absolutely discharged or conditionally discharged and this discharge rate of around $15 \%$ is near average for regions without a special hospital.

Meanwood Park Hospital

DOUglas A. SPENCER

Leeds

\section{Schizophrenia in ethnic minorities}

\section{DeAr SiRS}

The question of schizophrenia in ethnic minorities in Britain has been the subject of recent publications and a leading article in the $B M J$. Since there is some unease about the content of these reports and their impact on medical and lay audiences, the Executive Committee of the Transcultural Psychiatry Society (UK), of which I am the current Chairperson, has agreed the following statement:

(1) Schizophrenia as a concept used in medical circles to denote an illness is as much socially constructed as it is biologically determined. In the present state of social and medical knowledge, the diagnosis of schizophrenia tells us as much about the biases in our society and in the person making the diagnosis, as it does about the 'patient'.

(2) The effects of research published in scientific journals must take into account the prevailing political context. It is naive to assume that research on issues involving race are value free when conducted in a racist society, within a discipline, such as psychiatry, with a powerful racist tradition.

(3) While accepting that schizophrenia is diagnosed to a relatively disproportionate extent among black people in the United Kingdom, we deplore the impression that may have been given in some recent publications that this fact reflects a biological inferiority of Blacks in comparison to Whites. In particular, we are concerned to hear that these reports may lead to studies which concentrate on genetics of black people to the exclusion of other issues and/or the investigation of possible virus infections being carried by Blacks. We believe that such studies will have seriously damaging political implications for black people in this country in the present political context of racism while any conclusions drawn from such research are likely to be, at best, of very limited use, and, at worst, extremely misleading, given the present state of knowledge in psychiatry.

(end of agreed statement)

Everyone recognises the fact that the advancement of knowledge needs a 'free press' for the reporting of findings and observations that are useful - and this applies to psychiatric journals as much as to others. However, it is naive to assume that researchers are unaffected by social and political pressures and attitudes, and, it is unrealistic to view published reports as devoid of political influence. In fact, conclusions arrived at in a subject like psychiatry where objectivity in measurement is uncertain often represent (to some extent at least) preconceptions of researchers. And tentative reports and hypotheses once reported in print may be used to reinforce popular misconceptions.

I believe that, in a society like ours that is far from perfect, the value of any particular publication must be seen in terms of a balance of pros and cons seen on a wide canvas. We have seen how the writings of psychologists in the 1930 s provided nourishment to the eugenic movement and the rise of Nazism. The revival of this 'racist IQ movement' in the 1970s is still very much alive and we may now be entering the age of the 'new eugenics' (Kevles, 1986). I believe that papers, such as that by Harrison et al (1988) published in Psychological Medicine, are potentially as dangerous in this day and age as the paper by Jensen (1969) that led to "linkage of IQ and educational policy with race' (Kevles, 1986)-with resulting grave disadvantage to black Americans. The dangers are only too evident in the press report of the Harrison paper headlined 'Young blacks vulnerable to schizophrenia' (Ballantyne, 1988). 
Although the statement agreed by our Society refers to papers on schizophrenia, the principles apply more generally to all publications in psychiatric journals. Perhaps it is time that responsible journals institute sensitive systems for evaluating papers submitted to them whenever such papers are concerned with questions of race so that their overall worth in the context of the realities of the society that we live in at present may be assessed.

SUMAN FERNANDO

Chase Farm Hospital

Enfield, Middlesex

\section{References}

BallantYNe, A. (1988) Young blacks vulnerable to schizophrenia. The Guardian, 31 October, p. 6.

HARRISON, G. et al (1988) A prospective study of severe mental disorder in Afro-Caribbean patients. Psychological Medicine, 18, 643-657.

Jensen, A. R. (1969) How much can we boost IQ and scholastic achievement? Harvard Educational Review, 39, 1-123.

KeVles, D. J. (1986) In the Name of Eugenics. Harmondsworth: Penguin.

\section{DEAR SIRS}

This letter is a timely reminder of the need for caution and sensitivity in researching psychiatric disorders and ethnic groups. The author rightly points to the way in which biomedical scientists themselves participated in the construction of Nazi racial policy (Proctor, 1988), and to the outrageous statements on race which have been made by psychiatrists. Research into different patterns of illness in ethnic groupings could be undertaken for sinister reasons, and their findings may certainly be misconstrued by the general public.

However, it is unsatisfactory to accept that schizophrenia is diagnosed to a disproportionate extent among black people, while effectively calling upon journal editors to censor publication of attempts to discover why this might be the case. If we are to be deprived of research findings which can be analysed, replicated and challenged, what are the alternatives? It seems that we must rely upon assertions made by various pressure groups and upon anecdotal media reports about the scale of 'misdiagnosis' of black people.

When considering variations in rates of any illness it is, of course, important to consider differences in service utilisation and the social geography of patients included in studies (Harrison et al, in press). However, if differences persist after taking such factors into account, then it is in the nature of scientific enquiry to consider all possible explanations. Personally, I believe that genetic factors are relatively unimportant in relation to the higher rates of psy- choses in Afro-Caribbeans. But my personal views, and for that matter those of anybody else interested in commenting upon these issues, must be subject to scientific scrutiny.

There is widespread concern that our psychiatric services should be sensitive to the needs of ethnic groups. However, it is surely naive to think that we can make sensible plans for development of services and treatments without at least attempting to measure symptoms in a standardised way and to relate treatment outcome to diagnostic profile. Services based upon vague impressions and good intentions simply will not do.

It is important to emphasise that many conditions (e.g. neural tube defects and Down's Syndrome) have substantially lower rates in Afro-Caribbeans. Because of the stigma attached to mental illness, findings of higher rates of schizophrenia and related psychoses call for considerable care in their interpretation.

However, to attempt to censor the findings of scientific enquiry or restrict the consideration of all possible explanations is unacceptable. It places us on an even more dangerous course which, interestingly, also has its precedents in the Nazi era.

Department of Psychiatry

GLYNN HARRISON

University of Nottingham Medical School

Nottingham

\section{References}

Harrison, G., Holton, A., NeIlson, D., OWEns, D., Boot, D. \& COOPER, J. Severe mental disorder in AfroCaribbean patients: some social, demographic and service factors. Psychological Medicine (in press).

Proctor, R. N. (1988) Racial Hygiene: Medicine under the Nazis. Harvard University Press.

\section{Towards a working definition of the long-term mentally ill}

DEAR SIRS

We appeal to your correspondents for examples of the above.

The Community Mental Health Centre movement pioneered in the USA is accused of having neglected the needs of long-term mentally ill (LTMI) people and of having drifted towards the care of patients more immediately responsive to treatment. Attempting to learn from this lesson, the mental health team operating from this office in Battersea (DEW) was established with a brief to give priority to LTMI patients. Over the past three years we have established a case-management style of working, an outline of which is given below. This way of dealing with patients is expensive as compared with traditional out-patient care or CPN care, because of the 